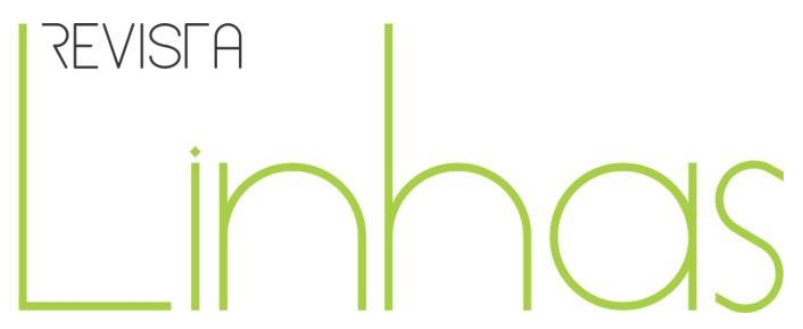

\title{
Educação, infância e nacionalismo: uma abordagem a partir das cartilhas escolares "Getúlio Vargas para crianças" e "Getúlio Vargas: o amigo das crianças"
}

\begin{abstract}
Resumo
O presente artigo discute as cartilhas escolares como fontes de leitura e de difusão do nacionalismo no contexto do Estado Novo, assim como a concepção de educação e de infância que delas pode emergir. Para dar conta desse objetivo, duas cartilhas são selecionadas: "Getúlio Vargas para crianças" (1942) e "Getúlio Vargas, amigo das crianças" (1940). A abordagem teórica e conceitual sobre o tema se ancora no horizonte teórico oferecido por Roger Chartier, sobretudo no que diz respeito às noções complementares de "representações" e "práticas" sociais. A análise realizada permite inferir que as cartilhas escolares refletem facetas significativas da relação entre nacionalismo e educação no período. De modo específico, revelam aspectos de um projeto político dedicado a difundir no imaginário infantil, princípios básicos da mentalidade que deu suporte ideológico ao regime varguista: autoridade, hierarquia, ordem e patriotismo.
\end{abstract}

Palavras-chave: Cartilhas Escolares. Infância. Estado Novo. História da Educação.

\author{
Zenaide Inês Schmitz \\ Universidade Comunitária da \\ Região de Chapecó - \\ Unochapecó - Santa \\ Catarina/Brasil
}

zenaideines@yahoo.com.br

Miguel Ângelo Silva da Costa

Universidade Comunitária da

Região de Chapecó -

Unochapecó - Santa

Catarina/Brasil

migguelcosta@gmail.com

\section{Para citar este artigo:}

SCHMITZ, Zenaide Inês; COSTA, Miguel Ângelo Silva da. Educação, infância e nacionalismo: uma abordagem a partir das cartilhas escolares "Getúlio Vargas para crianças" e "Getúlio Vargas: o amigo das crianças". Revista Linhas. Florianópolis, v. 18, n. 36, p. 377-404, jan./abr. 2017. 


\title{
Education, childhood and nationalism: an approach through the scholar booklets "Getúlio Vargas for children" and "Getúlio Vargas: friend of the children"
}

\begin{abstract}
The following paper aims to discuss the use of scholar booklets as source of reading and diffusion of nationalism in the context of the New State configuration, as well as the conceptions of education and childhood that can emerge from them. In order to fulfill this objective two booklets were selected: Getúlio Vargas for children (1942) and Getúlio Vargas: the friend of the children (1940). The theoretical approach is based on the conceptual horizon offered by Roger Chartier, above all in relation to the complementary notions of "social representation" and "social practices". The results of the analysis imply that the scholar booklets reflect meaningful details of the relation between nationalism and education in this period of time. They specifically reveal aspects of a political project dedicated to spread in in the collective imaginary of children, basic principles of the mindset that supported Vargas regime, such as authority, hierarchy, order and patriotism.
\end{abstract}

Keywords: Scholar Bbooklets. Childhood. New State. History of Education. 


\section{Primeiras palavras}

Aos 10 dias de novembro de 1937, na esteira da crise de 1929 e sob os efeitos dos desajustes econômicos, políticos e sociais com os quais a sociedade brasileira convivia, Getúlio Dorneles Vargas, em pronunciamento à nação, deu início ao regime que ficou conhecido na história política brasileira como Estado Novo (1937-45).

A partir de então, um amplo e poderoso aparato propagandístico emergiu articulado ao monopólio simbólico emanado do Estado. Criado, por decreto presidencial em 1939 e vinculado à presidência da República, o Departamento de Imprensa e Propaganda (DIP), por meio de propaganda política e sofisticada produção editorial, encarregou-se de difundir na opinião pública os princípios da autoridade, hierarquia, ordem e patriotismo. Vale mencionar, princípios básicos da mentalidade que deu suporte ideológico ao regime implantado em 1937.

Entre os distintos campos/ suportes de produção, difusão e legitimação do ideário nacionalista, as cartilhas escolares emergem não apenas articuladas à política de escolarização primária, mas, também, ao projeto político mais amplo emanado do Estado.

Inscrito, portanto, no campo temático da História da Educação e, a partir da relação entre Educação e Nacionalismo, o propósito deste artigo consiste em colocar em tela o papel das cartilhas escolares enquanto fontes de leitura e de difusão do ideário nacionalista no contexto do Estado Novo, assim como a concepção de educação e de infância que delas pode emergir. Em diálogo com o horizonte teórico oferecido por Roger Chartier (1990), sobretudo no que diz respeito às noções complementares de "representações" e "práticas" sociais, o trabalho concentra-se em duas fontes específicas: as cartilhas "Getúlio Vargas para Crianças" e "Getúlio Vargas: o amigo das crianças"; a primeira de autoria de Alfredo Barroso (1942) e a segunda possivelmente produzida pelo Departamento de Imprensa e Propaganda (DIP), em 1940. 


\section{As cartilhas escolares e a História da Educação: algumas aproximações epistemológicas}

Diversos estudos, sob distintos ângulos têm colocado em evidência a renovação que a historiografia da educação vivenciou, sobretudo a partir das décadas de 1980 e 90, com o incremento da pós-graduação no Brasil. Mas, evidentemente, esse processo de renovação dos estudos históricos educacionais não deve ser pensado apenas à luz do incremento e consolidação da pós-graduação stricto sensu no país. Vários fatores concorreram para que a história da educação brasileira adquirisse um estatuto de pesquisa, em substituição à tendência disciplinar, ou melhor dito, de componente curricular voltado aos cursos de graduação dedicados à formação de professores.

Primeiramente, há que se destacar o próprio diálogo estabelecido com a renovação da historiografia de uma forma geral em curso "do lado de lá" do Atlântico, não somente, mas em particular na França, desde a década de 1950. Se este diálogo transatlântico, conforme bem observado por Libânia Xavier e Fábio Garcez de Carvalho (2013, p. 232), concorreu para que a história da educação se emancipasse, gradativamente, de sua vocação de disciplina acadêmica, assim como de outros domínios disciplinares conexos, como a filosofia da educação e a sociologia da educação, ele também colocou em evidência um complexo repertório de questionamentos acerca dos pressupostos de pesquisa histórica em educação no país. É possível mesmo considerar que, desde que passou a ser entendida como dotada de historicidade, ou seja, condicionada pelo ponto de vista de quem a produz, pelo tempo e lugar de sua produção, a pesquisa e a escrita da história da educação passaram a demandar abordagem crítica das produções historiográficas precedentes. Isso significa dizer que o mesmo movimento de crítica historiográfica que colocou em questionamento os ditos "velhos" paradigmas epistemológicos, particularmente as concepções marxista e positivista da História, também incidiu sobre a história da educação, levando-a a considerar outros objetos e outros problemas na complexa agenda dos estudos históricos educacionais.

Em segundo lugar, partindo da historicidade inerente a esta nova etapa epistemológica, podemos considerar que, independentemente das opções teóricas emergentes, ela encontrou eco na criação de grupos de trabalhos destinados a promover a aproximação/ interlocução de pesquisadores dedicados a investigar a história da 
educação com maior densidade no país. A ponta de lança desse processo ocorreu no âmbito da Associação Nacional de Pós-graduação e Pesquisa em Educação (Anped), quando, no início da década de 1980, mais especificamente na $7^{\mathrm{a}}$ Reunião Anual da Anped, foi criado o Grupo de Trabalho História da Educação (SAVIANI et al, 2011).

A criação do GT História da Educação contribui para que, a partir de então, não apenas houvesse um debate teórico, temático e metodológico mais sistematizado, como, também, para que esse movimento de revisão crítica acerca dos padrões historiográficos, até então dominantes, fosse ampliado e difundido entre pesquisadores da área. ${ }^{1}$

Praticamente uma década após a criação do GT História da Educação, o debate intelectual que dele emergiu se ancorou em três grandes linhas de reflexão. A primeira contemplou a clássica tensão entre fontes, pesquisa histórica e acervos. Nessa linha de reflexão, o debate incidiu na crítica documental e o uso de novas fontes nos acervos e políticas institucionais de preservação do patrimônio documental educacional brasileiro (SAVIANI et al, 2011, p. 17).

Se a segunda linha de debate promoveu importante inflexão teórico-metodológica acerca das relações entre gênero e educação, a terceira, a partir da interlocução com a vertente francesa da Nova História Cultural, "fortaleceu o processo de renovação em curso pela incorporação de referenciais teóricos que evidenciavam a historicidade do lugar de produção da prática historiográfica” (SAVIANI et al, 2011, p. 17). Mas não só isso, além de colocar "em cena a necessidade de historicizar a linguagem das fontes e das ferramentas conceituais da pesquisa", essa linha de reflexão também colocou em cena os processos históricos de constituição dos objetos investigados, ampliando, desse modo, perspectivas de investigação até então pouco exploradas pela historiografia educacional brasileira (SAVIANI et al, 2011, p. 17-18).

A influência da chamada Nova História Cultural na recente historiografia educacional brasileira foi analisada por diferentes historiadores da educação. Mesmo que existam pontos de discordância, o que é comum em estudos de revisão, esses intelectuais são unânimes quanto às contribuições da História Cultural no processo de renovação dos

\footnotetext{
${ }^{1}$ Nesse processo, também deve ser destacada a criação, em 1986, do grupo de pesquisa História, Sociedade e Educação no Brasil (HISTEDBR), vinculado à Universidade Estadual de Campinas (UNICAMP), assim como, na década de 1990, a fundação da Sociedade Brasileira da História da Educação (SBHE). Para mais detalhes, ver: (SAVIANI et al, 2011).
} 
estudos históricos educacionais no Brasil, principalmente no que diz respeito à perspectiva de ampliação dos objetos, das abordagens e das fontes de pesquisa. ${ }^{2} \mathrm{Na}$ esteira das palavras de Diana Gonçalves Vidal e Luciano Faria Filho (2003, p. 60), em certa medida, essa nova postura historiográfica tem significado para os historiadores da educação "uma forma de marcar o seu pertencimento à comunidade dos historiadores, e uma maneira de reafirmar a identificação de suas pesquisas com procedimentos próprios ao fazer historiográfico".

Todavia, mesmo que seja inegável a mudança no perfil da pesquisa em História da educação no país e a influência que a História Cultural tem exercido sobre ela, é necessário, conforme sinaliza Thais Nívia de Lima e Fonseca (2008, p. 60-61), reconhecer que a penetração dos pressupostos da História Cultural é ainda problemática. Segundo a historiadora, problemática por conta de superposições de abordagens tradicionais, não raro marcadas por incorporações superficiais dos instrumentos conceituais e metodológicos (FONSECA, 2008, p. 61).

A essa altura, repetir que a renovação epistemológica da historiografia educacional brasileira encontrou eco na "Nova História Cultural” parecer redundante, até porque, outros historiadores dedicados à história da historiografia da educação, já demonstraram com significativa competência essa tendência. Contudo, parece-nos necessário melhor esclarecer que tendência da História Cultural tem exercido maior influência entre os historiadores da educação, visto que, como sabemos, desde as últimas décadas do século passado, o diálogo interdisciplinar envolvendo as relações da História com outros campos de saber, como a Antropologia, a linguística, a psicologia ou a ciência política tem gerado diversas correntes no âmbito da História Cultural (BARROS, 2011, p. $39) .^{3}$

Qualquer afirmação mais consistente acerca da corrente que exerceu maior influência nesse processo de renovação historiográfico exigiria, evidentemente, um esforço de análise impossível de ser realizado nas páginas desse artigo. Mais do que isso, acabaria redundando em praticamente outro artigo, dada a complexidade inerente ao

\footnotetext{
${ }^{2}$ Ver, entre outros: Clarice Nunes e Marta Carvalho (1993); Denice Catani e Luciano Faria Filho (2002); Diana Gonçalves Vidal e Luciano Faria Filho (2005); Thais Nívia de Lima e Fonseca (2008); Maurilane Biccas (2012).

${ }^{3}$ Para um exame mais detalhado acerca das distintas correntes da História Cultural, ver, entre outros: HUNT (2001); BURKE (2005); BARROS (2011).
} 
empreendimento. Contudo, as palavras da Thais Nívia de Lima Fonseca (2008) permitem inferir uma forte tendência de estudos ancorados nas reflexões de Roger Chartier, principalmente em seus conceitos de representação e apropriação. Ainda segundo a historiadora, em diálogo com o principal campo de investigação deste historiador francês, a história da leitura e dos impressos "tem concentrado parte significativa dos estudos apresentados em congressos e desenvolvidos como dissertações e teses" (FONSECA, 2008, p. 60).

A História Cultural na perspectiva apontada por Thais Nívia de Lima Fonseca e outros intelectuais já citados nesse artigo, tem como objetivo "identificar o modo como, em diferentes lugares e momentos, uma determinada realidade é construída, pensada, dada a ler" (CHARTIER, 1990, p. 16-17). Assim entendida, a História Cultural, para Roger Chartier (1990), busca o estudo dos objetos com os quais os sujeitos constroem sentidos sobre suas ações, na relação, mas não necessariamente na submissão a atores sociais. Foi justamente na perspectiva de recuperar esses sujeitos, que o historiador francês formulou a noção de "representação". Para Chartier (1990, p. 23), a noção de “representação" deve ser pensada de modo articulado a três modalidades de relação com o mundo social:

Em primeiro lugar, o trabalho de classificação e de delimitação que produz as configurações intelectuais múltiplas, através dos quais a realidade é contraditoriamente construída pelos diferentes grupos; seguidamente, as práticas que visam fazer reconhecer uma identidade social, exibir uma maneira própria de estar no mundo, significar simbolicamente um estatuto e uma posição; por fim, as formas institucionalizadas e objectivadas graças as quais uns 'representantes' marcam de forma visível e perturbada a existência do grupo, da classe ou da comunidade.

Em diálogo com esta perspectiva analítica, Roger Chartier dedica-se, entre outros temas, à história da leitura e dos impressos. Os livros e/ ou impressos são analisados em suas produções como objetos culturais e o que representam aos seus leitores. Neste processo analítico, atenta para os dispositivos textuais que dão sentido à realidade 
construída e expressa nessas fontes, de modo a apreender o universo sociocultural retratado pelos autores.

Baseado nos estudos de Don Mackenzie, Roger Chartier (2002, p. 64) coloca em tela a importância de o historiador incluir em suas análises, independente do gênero ou estatuto, as "categorias de citação, de designação e de classificação de acordo com o tempo e lugar que lhe são próprios" e, ao mesmo tempo, as formas que compõem o texto, como "o formato do livro, a construção da página, a divisão do texto, a presença ou ausência das imagens, as convenções tipográficas e a pontuação", além, evidentemente, dos próprios significados que procuram transmitir (CHARTIER, 2010, p. 7).

De acordo com Chartier (2002), o processo de publicação de um texto sempre é coletivo, já que implica sempre numa pluralidade de espaços, de técnicas, de máquinas e indivíduos. Encontrar as diferentes decisões e intervenções que deram aos textos impressos suas diferentes formas materiais é chegar às profundezas do próprio texto.

Foi na esteira dessa nova etapa epistemológica vivenciada pela historiografia educacional brasileira, que os impressos e suas possíveis formas de apropriação nas práticas escolares receberam maior interesse dos historiadores da educação. Alain Choppin (2004) e Orlando José de Almeida Filho (2007), embora com enfoque em realidades distintas - o primeiro concentrado na realidade francesa e, o segundo, na brasileira - observam que a história da leitura e dos impressos escolares - sejam eles livros didáticos ou não - ganhou maior relevo no âmbito de reflexões dedicadas aos processos de escolarização, à cultura escolar e às práticas educativas e pedagógicas. Mas não só isso, Choppin (2004) e Almeida Filho (2007) também sinalizam para a importância da natureza epistemológica, das narrativas e dos discursos embutidos nessas fontes de pesquisa.

Nessa mesma direção, Rosa Lydia Teixeira Côrrea (2000, p. 12), ao se referir aos livros e manuais escolares como fonte de pesquisa, atenta para dois aspectos fundamentais: 
Primeiro, trata-se de um tipo de material de significativa contribuição para a história do pensamento e das práticas educativas ao lado de outras fontes escritas, orais e iconográficas e, segundo, são portadores de conteúdos reveladores de representações e valores predominantes num certo período de uma sociedade que, simultaneamente à historiografia da educação e da teoria da história, permitem rediscutir intenções e projetos de construção e de formação social.

Percebe-se, portanto, que os impressos escolares, sejam eles livros didáticos ou cartilhas escolares, não estão deslocados do contexto político e cultural da época em que foram produzidos e, por isso, não raro foram utilizados como legitimação de um sistema de poder. Enquanto parte de políticas oficiais do Estado, essas fontes se constituem num suporte de interlocução que veiculam valores e ideologias. Encaradas como mediadoras de representações políticas e culturais de uma determinada sociedade, elas permitem conhecer o modo como determinada sociedade estabeleceu relação com sua história e seu passado.

De outra parte, conforme bem observado por Ana Maria de Oliveira Galvão e Antônio Augusto Gomes Batista (2008, p. 164), isso não significa que os livros e/ ou impressos escolares não possuam especificidades enquanto fontes ou que devam ser reduzidos à mera expressão da história das mudanças estruturais vivenciadas por uma dada sociedade. Enquanto produções culturais dotadas de alta complexidade, apresentam um conjunto de possibilidades investigativas que articulam diversas dimensões analíticas, entre as quais, a epistemológica.

Na esteira dessa postura investigativa é possível ir além das representações do mundo social expressas nas cartilhas escolares. Todavia, um estudo com base nessas fontes também exige explorar a "materialidade do texto", ou seja, analisar o processo pelo qual os diferentes atores envolvidos com sua publicação dão sentido aos textos impressos e dados a ler, rompendo, desse modo, com uma relativa abstração textual, na qual o texto acaba reduzido a seu conteúdo semântico, independente de sua materialidade (CHARTIER, 2002).

A ampliação das possibilidades de abordagem, assim como o próprio uso das cartilhas escolares, dos livros didáticos e dos manuais escolares como fonte para pesquisa 
histórica, emerge imiscuída a esta nova etapa da historiografia educacional brasileira. $\mathrm{O}$ contributo de Roger Chartier, assim como de outros intelectuais dedicados à história da leitura e dos livros, contribuiu e tem contribuído para que a análise dessa natureza não se restrinja meramente ao estudo do texto. Com esse entendimento, parece possível encontrar estratégias metodológicas dedicadas à análise dos mecanismos de produção, circulação e apropriação, expressos nas representações, na materialidade do texto, no domínio das práticas sociais de apropriação.

Se até aqui procuramos tecer algumas aproximações de cunho epistemológico entre as cartilhas escolares (como fonte) e a história da educação numa perspectiva ancorada no horizonte teórico oferecido pela Nova História Cultural, a meta a partir de agora consiste em colocar em tela o papel das cartilhas escolares enquanto fontes de leitura e de difusão do ideário nacionalista no contexto do Estado Novo, assim como a concepção de educação e de infância que delas pode emergir.

\section{Educação, infância e nacionalismo a partir das cartilhas escolares}

Segundo Stuart Hall (2011, p. 49), "as identidades nacionais não são coisas com as quais nascemos, mas são formadas e transformadas no interior da representação". Na esteira deste raciocínio, pode-se considerar que a ditadura varguista - o Estado Novo -, registrou significativas mudanças de sentido na sociedade de então. A Educação, ou melhor, o sistema educacional naquele período, em sincronia com o projeto de nacionalização compulsória empreendido, contribuiu decisivamente para a construção de novos sentidos de pertencimento à nação.

A ideologia do cidadão trabalhador e o discurso acerca da necessária modernização do país ganharam corpo desde cedo. Do ensino primário ao superior, crianças, jovens e adultos foram alvos de uma forte e eficiente propaganda ideológica tecida em diálogo com intelectuais atrelados ao projeto nacionalista implantado. Não à toa nomes como o de Oliveira Viana, Francisco Campos, Azevedo Amaral, entre outros, despontaram com vigor no cenário político-social brasileiro (OLIVEIRA, 1990).

Luciano Aronne de Abreu (2008), por exemplo, observa que o golpe de 10 de novembro de 1937 foi defendido por uma elite intelectual dedicada a promover a 
necessária adequação entre "política" e "espírito nacional”, questão fundamental para a desejada harmonia social. Entre esses intelectuais, Francisco Oliveira Vianna, que também atuou como consultor jurídico do Ministério do Trabalho na década de 1930, despontou como um dos principais, se não o principal teórico da ideologia do Estado autoritário brasileiro (GOMES, 2005).

Para Ângela de Castro Gomes (2005, p. 110), enquanto um dos intelectuais integrantes da montagem do pensamento autoritário, Oliveira Vianna "exerceu inequívoca influência, entre seus contemporâneos, que com ele foram forçados a debater, quer com ele concordassem quer dele discordassem". Mas não só isso, ainda segundo Castro Gomes (2005), no campo político, ao oferecer subsídios para uma proposta autoritária, Oliveira Vianna também contribui para configuração de uma “engenharia política corporativa” dedicada à implementação do Estado Novo.

Foi justamente isso que Luciano Aronne de Abreu (2008) também observou em análise dedicada ao pensamento de Oliveira Vianna e suas interfaces com o Estado Novo. Para o historiador, a associação entre o regime autoritário e um suposto realismo político proposta por Vianna, passou pela necessidade de "subordinar os interesses dos indivíduos, clãs ou partidos ao interesse coletivo”. No raciocínio de Oliveira Vianna, isso "seria expresso precisamente pela capacidade de obediência e disciplina, pelo culto do Estado e de sua autoridade" (ABREU, 2008, p. 54).

Em síntese, a "moral da história”, segundo Luciano Aronne de Abreu (2008), é a de que "obediência e autoridade" colocavam-se como condições essenciais para a manutenção da ordem e o desenvolvimento de uma nação, "na qual o Estado seria o cérebro e os demais órgãos - grupos, classes, profissões - desempenhariam diferentes funções, complementares entre si, formando um todo harmônico" (ABREU, 2008, p. 55).

Se Oliveira Vianna se envolveu no processo de construção de um arcabouço institucional para o Estado republicano, intelectuais como Francisco Campos e Azevedo Amaral também se envolveram na elaboração de um projeto que combatesse o criticado atraso do Brasil. Para Maria Célia Marcondes de Moraes (2000), a proposta de Francisco Campos refletia um projeto de nação no qual não houvesse espaço para "ideologia exótica". Assim, a especificidade do Estado Novo para Francisco Campos residia 
justamente na construção de um novo Brasil, sob o ponto de vista econômico, político, social e educacional.

$\mathrm{Na}$ política, eliminando-se as instituições liberais, restringindo-se drasticamente o poder legislativo do Parlamento em favor do executivo, limitando-se as liberdades e garantias individuais, estabelecendo-se controle e censura à imprensa. Na economia, organizando-se a economia nacional pela solidariedade entre capital e trabalho mediante a estrutura corporativa, mantendo-se, portanto, inalterado o apoio aos aspectos básicos da ordem capitalista. Na educação atendendo-se às exigências do estado atual de civilização e de cultura. (MORAES, 2000, p. 181)

No pensamento de Francisco Campos, e o mesmo pode ser dito em relação ao de Azevedo Amaral, a sociedade brasileira não dispunha de maturidade política suficiente para exercer seu direito de participação nos processos decisórios do país. A suposta ausência de consciência política, questão de longa data presente no debate político brasileiro, poderia colocar em risco o destino do país, uma vez que indivíduos sem a devida maturidade política poderiam ascender às instâncias superiores do governo. Daí a defesa de um homem forte nas rédeas da nação. Daí também a necessidade de difundir no imaginário social da época uma figura mítica, que fosse capaz de deflagrar o necessário processo de integração e de modernização da nação. Vargas, por não ter antecedentes que rivalizassem com ele em prestígio, foi o escolhido (GOMES, 2005, p. 116).

$\mathrm{Na}$ construção do Estado Nacional, o discurso propagandístico articulou-se à necessidade da formação de uma grande família nacional, em que o presidente Vargas era o "pai" e os filhos o "povo nobre e trabalhador" e, onde, nas palavras de Azevedo Amaral (apud GOMES, 2005, p. 112), "a democracia nova só comporta um único partido: o partido do Estado, que é também o partido da Nação".

A produção historiográfica acerca da influência dos "intelectuais orgânicos" na política implantada pelo Estado Novo é ampla e diversificada, de modo que não seria no espaço deste artigo que conseguiríamos dar conta do debate já realizado. O que, em realidade, importa aqui é o fato de que este forte e denso aparato político-ideológico permeou diferentes instâncias da sociabilidade inclusive as escolares. 
A Educação, ou melhor, o sistema de ensino e as práticas educativas - tanto no ensino primário como secundário - ao longo do Estado Novo, não apenas despontaram como parte deste projeto político emanado do Estado, como, também, acabaram assumindo um papel fundamental no que consiste a configuração de uma nova identidade nacional. Nagle (2001, p. 145), neste sentido, aponta que "a escolarização passou a ser vista como o instrumento do progresso histórico" dedicado a transformar o simples indivíduo em força produtiva: uma alternativa viável e necessária no processo de regeneração do indivíduo, de reconstrução da nacionalidade, quer sob o ponto de vista produtivo quer sob o ponto de vista da própria nacionalidade.

No processo de construção da "verdade doutrinária" propagada pelo regime e, em enquanto mediadores entre o Estado e a sociedade, a intelectualidade também se encarregou de produzir dispositivos culturais dedicados a ampliar o consumo de conteúdos doutrinários próprios. Em realidade, “imagens ricamente elaboradas e pensadas como operadores simbólicos" (LENHARO, 1986, p. 54) que, com rapidez e precisão, esvoaçaram sobre os diferentes segmentos da sociedade brasileira, inclusive sobre aqueles em idade escolar.

Segundo Diana Gonçalves Vidal (1998), durante a década de 1930, a leitura e os livros e/ou impressos escolares receberam forte atenção de educadores, políticos e do próprio estado. O livro passou a ser visto como uma fonte de experiência e, a leitura, não somente como acesso à informação, mas, sobretudo, como elemento (con)formador do imaginário coletivo infantil, o que contribuiu significativamente para o aumento de publicações.

As cartilhas escolares "Getúlio Vargas: o amigo das crianças" (1940) e "Getúlio Vargas para Crianças" (BARROSO, 1942), foram produzidas neste cenário e aqui serão analisadas como suportes de leitura e veículos difusores de um ideário construído em estreito diálogo com o debate intelectual da época. Produzidas pelo Departamento de Imprensa e Propaganda (DIP), essas fontes não tinham por finalidade apenas difundir no imaginário infantil os pressupostos nacionalistas. Por meio de conteúdos traduzidos em linguagem simples e de fácil acesso, as cartilhas, tais quais outros livretos editados no 
período, também foram pensadas com o intuito de modelar comportamentos, visões de mundo e de nação consideradas legítimas pelo governo estadonovista. ${ }^{4}$

Enquanto "livros de leitura", as cartilhas destinadas ao público infantil no contexto do Estado do Novo nos oferecem uma porta de entrada para um "mundo social" em construção, ou se quisermos, conforme Roger Chartier (1990, p. 17), para um mundo social no qual "os discursos não são neutros", visto que produzem "estratégias e práticas (sociais, escolares, políticas)" dedicadas "a impor uma autoridade à custa de outros, por elas menosprezados, a legitimar um projeto reformador ou a justificar, para os próprios indivíduos, as suas escolhas e condutas". Mas, afinal, que discursos e representações estariam impregnados nas cartilhas infantis? Elas realmente representam facetas do discurso nacionalista vigente na época? Seriam elas, de fato, veículos dedicados a difundir no imaginário do público infantil em idade escolar, os pressupostos nacionalistas? Então vejamos!

A cartilha "Getúlio Vargas: o amigo das crianças" (Figura 01) carrega um conteúdo de teor mais propagandístico. De 1940, o material tem 32 páginas, de formato $27 \times 19 \mathrm{~cm}$. Há 45 ilustrações ao longo da cartilha, sendo que destas, 34 retratam a imagem de Vargas e nenhuma é acompanhada de legenda. A linguagem utilizada é de simples compreensão e a informação é tratada diretamente numa linguagem denotativa, sem rodeios, o que permite considerar que o leitor aprenda o conteúdo com facilidade.

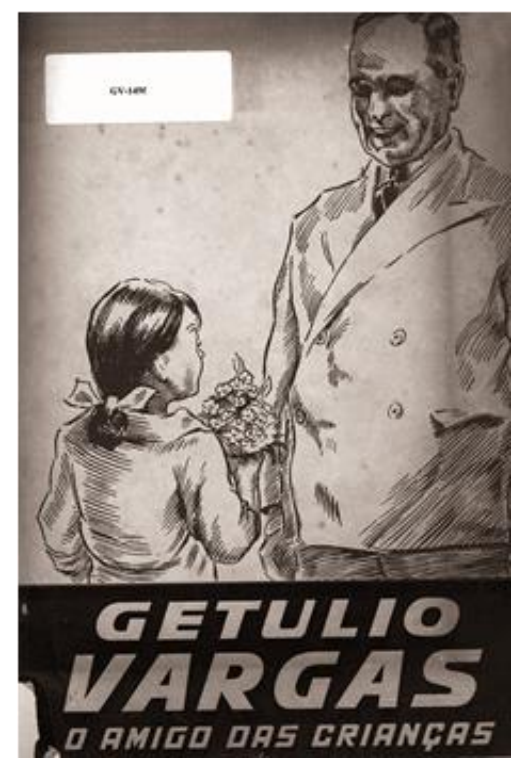

Figura 1. Capa da cartilha "Getúlio Vargas: o amigo das crianças".

Fonte: GETÚLIO Vargas (1940).

\footnotetext{
${ }^{4}$ As fontes aqui utilizadas foram consultadas no Centro de Pesquisa e Documentação de História Contemporânea do Brasil - CPDOC, da Fundação Getúlio Vargas, do Rio de Janeiro.
} 
O texto vem sem autoria, mas alguns indícios observados em sua materialidade (Figuras 02 e 03) indicam que o material tenha sido publicado pelo Departamento de Imprensa e Propaganda e que a impressão tenha sido feita pela gráfica Olímpica.

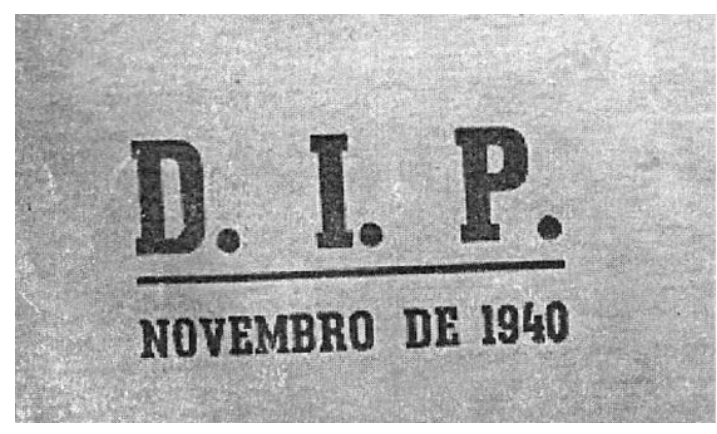

Figura 2. Carimbo do DIP presente no verso da capa da cartilha "Getúlio Vargas: o amigo das crianças".

Fonte: GETÚLIO Vargas (1940).

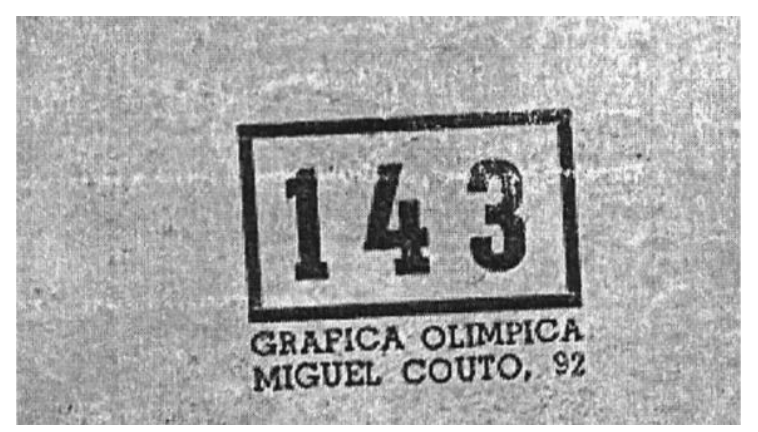

Figura 3. Carimbo da gráfica Olímpica presente na cartilha "Getúlio Vargas: o amigo das crianças".

Fonte: GETÚLIO Vargas (1940).

A importância de se atentar para esses detalhes que se encontram na cartilha consiste em se chegar à "alma do texto", ou seja,

[...] se o corpo do livro é o produto do trabalho feito por impressores ou pelos encadernadores, a criação de sua alma não envolve apenas a invenção do autor. A alma é moldada também pelos tipógrafos, editores ou revisores, que se encarregam da pontuação, da ortografia ou do layout do texto. (CHARTIER, 2002, p. 38)

Desta forma, a participação do DIP, assim como da Gráfica Olímpica, foram fundamentais para a estruturação do texto. O DIP, como propulsor da imagem do regime que se instalou em 1937, e a gráfica, como responsável pela impressão do material a ser divulgado.

Imerso em forte apelo emocional, o conteúdo da cartilha "Getúlio Vargas: o amigo das crianças" gravita em torno de argumentos dedicados a mostrar às crianças o amor de Vargas para com elas. Maria Helena Capelato (2009, p. 129), neste sentido, sugere que o uso de tal mecanismo "em se tratando de um público infantil", faz parte de uma estratégia na qual o discurso é direcionado a uma "personalidade ainda não formada 
completamente”. Por meio do Quadro 1 é possível observar a concentração temática que compõe a construção do texto

Quadro 1. Distribuição dos assuntos da cartilha "Getúlio Vargas: o amigo das crianças"

\begin{tabular}{c|l|c|c}
\hline Partes & \multicolumn{1}{|c|}{ Assuntos } & Páginas & \multicolumn{1}{c}{$\begin{array}{c}\text { Número de } \\
\text { ilustrações }\end{array}$} \\
\hline 1 & Crianças & 2 a 6 & 6 \\
\hline 2 & Regionalismo/nacionalismo & 6 a 10 & 19 \\
\hline 3 & Juventude brasileira & 10 a 25 & 8 \\
\hline 4 & Realizações para as crianças & 25 a 30 & 2 \\
\hline 5 & $\begin{array}{l}\text { Amizade de Vargas com as } \\
\text { crianças }\end{array}$ & 30 a 32 & 8 \\
\hline
\end{tabular}

Fonte: Elaboração própria com base na cartilha "Getúlio Vargas: o amigo das crianças".

Ao longo do texto, diversos dispositivos são utilizados como propósito de chamar a atenção do público leitor. Inicialmente, percebe-se um texto claro e objetivo, cujo propósito não parece ser outro, senão a comunicação direta com seu leitor. Também se observa expressiva repetição de certas palavras. Em conjunto, os léxicos Crianças, Getúlio Vargas, Juventude, Pátria e Amigo representam 145 ocorrências (Quadro 2). Conforme o Quadro 2, é possível perceber que os léxicos Crianças e Getúlio Vargas dominam a cena da narrativa, compreendendo 61\% das ocorrências.

Quadro 2. Léxicos que se destacam na cartilha "Getúlio Vargas: o amigo das crianças"

\begin{tabular}{c|c}
\hline Léxicos & Ocorrências \\
\hline Crianças & 46 \\
\hline Getúlio Vargas & 42 \\
\hline Juventude & 15 \\
\hline Pátria & 24 \\
\hline Amigo & 18 \\
\hline & 145 \\
\hline
\end{tabular}

Fonte: Elaboração própria com base na cartilha "Getúlio Vargas: o amigo das crianças".

Como é possível perceber, o léxico "Getúlio Vargas" aparece 42 vezes ao longo do texto, sendo que por várias vezes outras expressões como, presidente, ele, governo, 
chefe do governo, chefe da nação e chefe do estado também são utilizadas como forma de associação. A ênfase nessas palavras tem o intuito de chamar a atenção do leitor, atentando para os personagens principais do texto: Getúlio Vargas e as crianças. Portanto, a repetição nessa perspectiva torna-se necessária e a simples menção de seu nome seria o suficiente para criar uma memória.

Assim, a cartilha procura exprimir ao longo do texto o culto ao mito: Getúlio Vargas. Vargas emerge da narrativa como o "salvador da pátria", personagem que chega para resolver todos os problemas brasileiros. Palavras de empenho e energia, inteligência e perspicácia, eram atribuídas a sua figura, bem como diversas qualificações como belo, brilhante, constante, iluminado, ilustre, glorioso, heroico, imortal, invencível, justo, laborioso, piedoso, triunfante, sábio, vigilante.

Já, a cartilha "Getúlio Vargas para Crianças" (Figura 04) foi escrita por Alfredo Barroso, ilustrada por Francisco Dias da Silva e editada em 1942. Publicada pela Empresa de Publicações Infantis Ltda., no Rio de Janeiro, e financiada pelo Departamento de Imprensa e Propaganda. O formato do material é $13 \times 11,5 \mathrm{~cm}$, acompanhado de 112 páginas, sendo elas distribuídas entre um texto de tom formal, de fácil compreensão e de 52 ilustrações impressas em preto e branco. As ilustrações e o texto são ordenados em páginas duplas onde, de um lado, está o texto, e do outro, está a ilustração acompanhada de um trecho explicativo. Essa estratégia produzia o efeito de textualização da imagem.

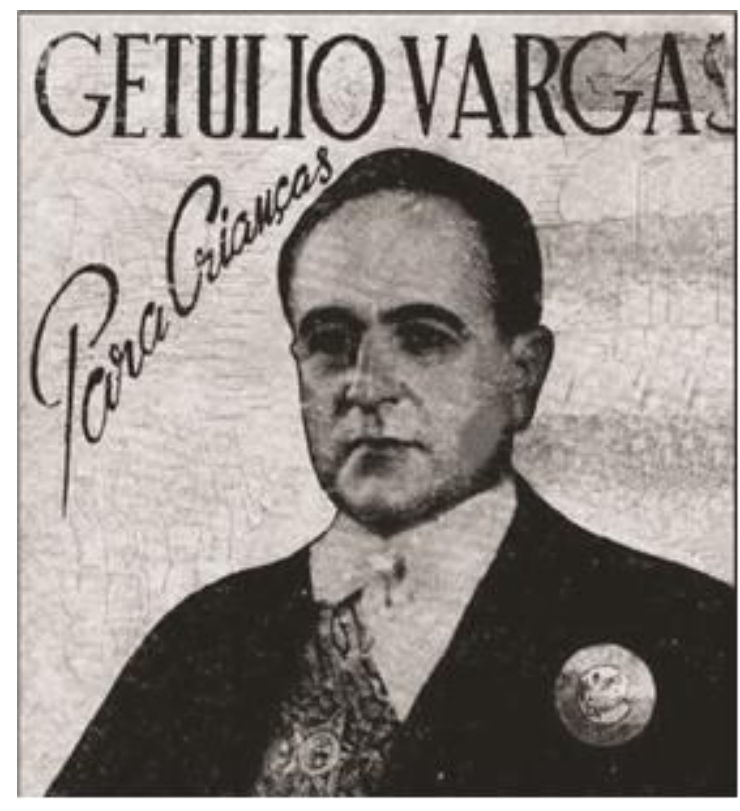

Figura 4. Capa da cartilha "Getúlio Vargas para Crianças".

Fonte: Barroso (1942). 
Para Gonçalo Júnior (2004), a cartilha "Getúlio Vargas para Crianças" faz parte da coleção denominada “Biblioteca Pátria” que é composta de 15 volumes, elaborada por Adolfo Eizen, um dos maiores escritores de Histórias em Quadrinhos na época. Eizen teria feito a produção do material no sentido de contribuir com o projeto político do Estado Novo e liquidar as dívidas de sua empresa. O que de fato teria ocorrido, pois vendeu várias tiragens ao governo, o que reforça a afirmação de Ângela de Castro Gomes (2003) de que escrever para crianças no Brasil, desde o início da República, passou a ser um comércio muito lucrativo. Assim, a edição de estreia, "Getúlio Vargas para Crianças", foi descrita como o livro padrão da juventude brasileira e passou a ser lido como um catecismo em todas as escolas. Ainda, segundo Gonçalo Júnior (2004, p. 84), o governo não revelou quantos exemplares comprou para distribuir nas escolas, mas sabia-se que a "cartilha teria se transformado num recorde na indústria editorial do Brasil”.

De outra parte, a cartilha foi significativamente elogiada pelo governo, tanto que, Eizen recebeu uma carta com elogios do Ministro da Justiça, Negrão de Lima, em virtude do lançamento de "Getúlio Vargas para Crianças":

Sr. Adolfo Eizen. Com sua atenciosa carta de 18 do corrente recebi o exemplar que o "Grande Consórcio Suplemento Nacional" teve a gentileza de enviar-me, do livro Getúlio Vargas para Crianças, com que acaba de enriquecer as letras nacionais, nesse importante setor relacionado à formação cívica da juventude. Muito agradeço a oferta e o prazer espiritual que o livro me proporcionou. Iniciativas dessa ordem, tendentes a focalizar perante as inteligências infantis e gravar na consciência cívica, ainda em formação, daqueles que serão os cidadãos de amanhã, e figura excelsa do Presidente Getúlio Vargas, merecem de todos quantos amam o nosso Brasil os mais decididos aplausos. Recebaos, pois essa empresa, com os agradecimentos do Negrão de Lima. (GONÇALO JÚNIOR, 2004, p. 85)

Deste modo, percebe-se que a estratégia de Eizen foi criar uma cartilha que atendesse aos interesses governamentais, possibilitando, desta forma, a venda ao governo, livrando, assim, sua empresa da falência. A cartilha atendia também os interesses da Comissão Nacional de Literatura Infantil $(\mathrm{CNLI})^{5}$, a qual prezava por livros

\footnotetext{
${ }^{5}$ Criada em 29 de abril de 1936, a Comissão tinha como atribuições realizar levantamentos sobre a situação desse tipo de produção literária; selecionar livros para serem traduzidos, classificar por idades as obras
} 
que valorizassem imagens, uma vez que havia o entendimento de que a fantasia deveria dominar, o que seria motivado pelo uso de imagens.

O que se constata em tal informação é que qualquer pessoa que produzisse uma obra enaltecendo o regime, a teria divulgada pelo governo. Nesse sentido, não é à toa observar que jornalistas, escritores e estudiosos se tornavam colaboradores do DIP que, no entendimento de Ângela de Castro Gomes (2003, p. 122), acenava a possibilidade "de ganhos materiais e simbólicos em estreito mercado editorial”.

Desta forma, observa-se que a intelectualidade foi além da formação e informação do leitor, mesmo estando engajada na proposta de construção de uma cultura cívica de legitimação do regime estadonovista, os intelectuais foram motivados também pelos interesses financeiros.

O conteúdo da cartilha dedica-se a criar representações de Getúlio Vargas a partir da narração de sua vida. Uma espécie de biografia, que inicia com informações sobre sua infância e vai até sua escalada à presidência. Durante esse percurso, são apresentadas informações sobre o Governo Provisório, sobre a Revolução de 1932, a Constituição de 1934 e a instauração do Estado Novo. Em resumo, é possível considerar que o cenário que compõe a cartilha é imenso (Quadro 03): vai do cotidiano simples, de uma vida tranquila de sua infância no Rio Grande do Sul, percorrendo situações inusitadas como participações em batalhas militares, até sua vida mais agitada no Rio de Janeiro, como Presidente da República.

Quadro 3. Distribuição dos capítulos da cartilha "Getúlio Vargas para crianças"

\begin{tabular}{c|l|c|c}
\hline Capítulos & \multicolumn{1}{c|}{ Títulos } & Páginas & $\begin{array}{c}\text { Número de } \\
\text { ilustrações }\end{array}$ \\
\hline 1 & Infância e estudos & 6 a 16 & 6 \\
\hline 2 & Vida militar & 17 a 28 & 6 \\
\hline 3 & De Ministro a Presidente & 29 a 39 & 5 \\
\hline 4 & A Revolução de outubro & 39 a 49 & 5 \\
\hline 5 & A Reconstrução Nacional & 49 a 82 & 16 \\
\hline 6 & O Estado Novo & 83 a 92 & 5 \\
\hline 7 & Força e trabalho & 93 a 108 & 8 \\
\hline 8 & O homem simples e bom & 109 a 112 & 2 \\
\hline
\end{tabular}

Fonte: Elaboração própria com base na cartilha "Getúlio Vargas para crianças". 
Nesta cartilha, alguns dispositivos também foram usados para obter a atenção do leitor. O Quadro 4 revela a recorrência exaustiva a certos chamamentos, em que não se poupa o léxico "Getúlio Vargas". Em 112 páginas, recorre-se 82 vezes ao nome do estadista, reforçando, assim, o argumento de que os rumos da história brasileira estavam fortemente atrelados à trajetória do Presidente.

\section{Quadro 4. Léxicos que se destacam na cartilha "Getúlio Vargas para crianças"}

\begin{tabular}{l|c}
\hline \multicolumn{1}{c|}{ Léxicos } & Ocorrências \\
\hline Crianças & 5 \\
\hline Getúlio Vargas & 82 \\
\hline Juventude & 3 \\
\hline Pátria & 2 \\
\hline & 92 \\
\hline
\end{tabular}

Fonte: Elaboração própria com base na cartilha "Getúlio Vargas para crianças".

Além disso, os personagens que emergem do texto têm nomes próprios e sobrenomes, como "Getúlio Vargas", "Manuel do Nascimento Vargas", "Candida Dornelles Vargas". Embora a narrativa coloque em evidência sua família, Vargas é, indiscutivelmente, o personagem principal.

Outra característica presente no texto da cartilha é a presença de marcadores temporais e espaciais. O leitor é convidado a traçar (no imaginário) uma linha temporal e espacial para localizar os acontecimentos que lhe são informados. Cabe, igualmente observar, que durante a narração da infância de Vargas até a presidência, houve a intenção de criar uma imagem positiva do personagem por meio de vários atributos a ele conferidos, apresentados como exemplos/ condutas a serem partilhados/ apropriados socialmente. Os requisitos de uma boa educação eram apresentados como parte da sua conduta. Recorrer a situações cotidianas de Vargas se constituiu em uma bela oportunidade para abordar a importância de hábitos a serem seguidos e, como salienta Rogério Luiz Souza (2014, p. 403), estes “não precisam de elementos reflexivos, como os das palavras, mas sim, do silêncio cúmplice ao ouvir".

No entanto, levando em consideração os apontamentos de Chartier (2002) para a análise de um impresso, percebe-se que vários dispositivos são utilizados para chamar a atenção das crianças e dos jovens nas cartilhas. Conforme já mencionado, mas vale 
reiterar, percebe-se que o texto das duas cartilhas aparece de forma clara e objetiva com relativo sentido metafórico, o que acaba contribuindo para a comunicação direta com seus leitores. Depois se observa a repetição de certas palavras em demasia. Geralmente, os léxicos que dominam a cena são "Crianças" e "Getúlio Vargas", sendo que em outros momentos, ao se referir às crianças, utilizaram-se outras expressões, como meninos, meninas, pequenos seres, criançada, garotada, meninada, moços e futuras gerações; e, ao se referir a Getúlio Vargas, foram usadas expressões como, presidente, ele, governo, chefe do governo, chefe da Nação e chefe do Estado.

Assim, percebe-se que a ênfase nessas palavras tem o intuito de chamar a atenção do leitor, atentando para os personagens principais dos textos: Getúlio Vargas e as crianças. Portanto, a repetição nessa perspectiva torna-se necessária e a simples menção de seu nome seria o suficiente para criar uma memória ou para criar o argumento de que a história brasileira se desenrola desta maneira por conta do Presidente. Além de reforçar o chamamento às crianças como as responsáveis pelo futuro da nação.

Além destes recursos linguísticos muito bem utilizados, observa-se a exaustão de ilustrações ao longo das cartilhas. As ilustrações trazem a imagem de crianças ou trazem a imagem de Getúlio Vargas, procurando reforçar ainda mais sua popularidade. Unir texto com imagem ultrapassa um recurso gráfico, nesse caso assume um papel pedagógico. É uma estratégia de linguagem utilizada para reforçar, através da imagem, o texto. Ademais, a ilustração é um recurso lúdico que atrai e diverte o leitor.

Esta operação de significação se refere ao que Roger Chartier (1996) chama de “protocolos de leitura”, ou seja, mecanismos que impõem ao leitor uma maneira de ler e uma mecânica literária que o coloca onde o autor deseja que esteja e que ajuda o leitor na correta compreensão do texto.

[...] a disposição e a divisão do texto, sua tipografia, sua ilustração. Esses procedimentos de produção de livros, não pertencem à escrita, mas à impressão, não são decididas pelo autor, mas pelo editor-livreiro e podem sugerir leituras diferentes de um mesmo texto. (CHARTIER, 1996, p. 96) 
E continua argumentando que "façam o que fizerem os autores, não escrevem livros, os livros não são de modo algum escritos. São manufaturados por escribas e outros artesãos, por mecânicos, outros engenheiros e por impressores e outras máquinas" (CHARTIER, 1990, p. 126).

Rosa Lídia Teixeira Corrêa (2000, p. 13) acrescenta que esse tipo de fonte pode servir como um indicador do projeto de formação social desencadeado pela escola, na medida em que possibilita uma aproximação maior com a "circulação de ideias sobre o que a escola deveria transmitir/ensinar e, ao mesmo tempo, saber qual concepção educativa estaria permeando a proposta de formação dos sujeitos escolares."

Nesse sentido, percorrendo o conteúdo e as ilustrações das cartilhas, observou-se a ampla gama de elementos presentes que permitem entender à concepção que o governo de Getúlio Vargas tinha em relação à educação e à criança. Ou seja, permite-nos ter acesso às representações de criança e aos modelos de comportamento considerados ideais para dado período e momento histórico.

Concepção que pode ser observada já na primeira página da cartilha "Getúlio Vargas: o amigo das crianças", na seguinte frase: “É preciso plasmar na cera virgem, que é a alma da criança, a alma da própria pátria” (GETúLIO Vargas, 1940, p. 1). Esta frase revela que, na concepção do governo, "a alma da pátria estaria na alma das crianças" e como estas tinham uma mentalidade totalmente "virgem", era um ser inacabado, precisavam ser moldadas. Vislumbra-se, desta forma, a imagem estereotipada de criança concebida como um indivíduo que chegava à escola totalmente desprovido de saberes. Acreditava-se plenamente que a criança reproduziria passivamente os comportamentos, as atitudes e os valores transpostos nos textos.

Na concepção do governo, a criança, por ter uma "alma sensível”, deveria ser cuidada, cultivada, acompanhada, disciplinada, para que pudesse frutificar como um bom cidadão no futuro. No entanto, é factível perceber a importância dada à educação “em seu poder de moldar a sociedade a partir da formação das mentes e da abertura de novos espaços de mobilidade social e participação" (SCHWARTZMAN et. al., 2000, p. 69).

Desde o século XIX, as escolas passaram a atender as demandas de disciplinarização, de socialização do pensamento e legitimação do ideário político. A 
escola consagrava-se como instituição de formação da infância e juventude. Os governos passaram a entender que a educação poderia contribuir na realização de seus projetos governamentais, como "produtora e reprodutora de novas dinâmicas de socialização expressa na difusão da cultura escrita, das ciências e dos ideais de Nação e Pátria" (VEIGA, 2007, p. 05).

Marta Maria Chagas de Carvalho (1998, p. 351) reforça tal perspectiva observando que a convicção de que a educação constitui a Nação norteou as práticas escolares dos anos 30, uma vez que "esta passa a ser o que agrega, condensa, unifica e constitui o corpo social da Nação." Nesse sentido, o ato de educar era o ato de modelar um material informe e plasmável, uma vez que a "alma nacional" era vista como latente e precisaria ganhar visibilidade. Para a autora, o que se esperava da educação no período era a "regeneração" da população brasileira, considerada o núcleo da nacionalidade.

Paralelo ao processo de valorização da educação como instrumento de conformação do sentimento nacionalista, é possível perceber também a importância dada à criança dentro dessa nova ordem social e o papel atribuído a elas no período. Ao referir-se à necessidade de difundir valores patrióticos na "alma da criança", o governo estadonovista pretendia inculcar valores considerados corretos e indispensáveis à formação das crianças.

Assim, "a concepção educacional da época visava orientar o comportamento da criança para atitudes socialmente desejáveis ou civilizadas” (VEIGA, 2007, p. 213), ou seja, a criança é representada pela ideia de que precisa ser recuperada ou "socializada" para a sociedade por meio da escola. A criança passa a ser visualizada como um ser legítimo dentro da sociedade.

O projeto nacional empreendido pelo Estado Novo vislumbrava o Brasil como um país do futuro e, neste horizonte desejado, a criança emergiu como o cidadão do amanhã. Neste projeto, o público infantil assumiu a condição de verdadeira "sementeira sagrada, cujas almas cândidas guardam o mais puro amor da Pátria e as esperanças do regime novo" (GETÚLIO Vargas, 1940, p. 22). Logo, necessitavam receber as "luzes da instrução" já nos primeiros anos de vida quando começavam a "aprender $O A B C$ " e quando passavam a conhecer a "grandeza do Brasil” (GETÚLIO Vargas, 1940, p. 22). 
Desta forma, a educação se revelou um importante dispositivo de formação do cidadão idealizado pelo Estado Novo. Através de práticas educativas dedicadas às gerações mais novas, a difusão do ideário da nacionalidade se ancorou nos livros escolares transformados em objetos de formação moral e cívica. A criança, nesse sentido, passou a ser compreendida como promessa de um futuro melhor no âmbito de uma nação soberana, tornando-se um dos alvos da propaganda de corte nacionalista dirigida pelo Estado (SCHMITZ; COSTA, 2014).

\section{Considerações finais}

Cada sociedade, em diferentes épocas, compreendeu e produziu seus escritos a seu modo. Conforme Nelly Novaes Coelho (2008, p. 28-31), "conhecer a literatura que cada época destinou às suas crianças, é conhecer os ideais e valores sobre os quais cada sociedade se fundamentou", visto que o "livro infantil é entendido como uma 'mensagem' (comunicação) entre um ator-adulto (o que possui a experiência do real) e um leitor-criança (o que deve adquirir tal experiência)".

Assim, conclui-se que os atos de ler e ouvir se transformaram em atos de aprendizagem que, na perspectiva da política governamental de Vargas, foram aproveitados para difundir os valores de uma política nacional centralizadora e homogeneizante. O público infantil, ou melhor, o "cidadão mirim", tornou-se alvo da política governamental e, ao que tudo indica, os mínimos detalhes foram observados para garantir sua eficácia. Por conta disso, os livros escolares produzidos pelo DIP, além de exercitarem a leitura e escrita, também procuravam repassar

um imenso repositório de conselhos de moral, de bom comportamento, de boa conduta, da piedade, de respeito ao próximo, de amor à família e à Pátria, de rememoração de feitos e datas considerados da "nacionalidade" ou da "humanidade" e até mesmo de exaltação ao regime político de plantão, além de tudo aquilo que se considera digno da formação da criança e do jovem: a natureza (e suas partes), o índio, o folclore, os "grandes vultos" da ciência, das artes, do desporto, da política etc., contanto que representem o otimismo, a perseverança, a abnegação, o altruísmo e todas essas atitudes tidas como nobres e elevadas. (MACIEL, et al, 2014, p. 60) 
Mas o historiador, como leitor de documentos, também denota sentido as suas leituras, movido por objetivos e expectativas. Embora ainda preliminar, o instigante contato com as cartilhas revelou que essas fontes constituem "uma unidade discursiva, produtora de ordenamentos, de afirmação de distâncias, de divisões" (CHARTIER, 1990, p. 28). Também permite-nos inferir, que sua materialidade encontra eco no projeto político desenvolvido pelo governo de Getúlio Vargas e que foram pensadas e articuladas como uma espécie de manual de civilidade. Como parte de um conjunto de medidas adotadas na área educacional, visavam se tornar uma ponte entre o governo e o público infantil, no intuito de modelar comportamentos e visões de mundo, a partir dos valores considerados legítimos pelo regime de então.

Infelizmente, não temos como dimensionar em que medida as cartilhas escolares aqui analisadas foram efetivamente distribuídas pelas regiões escolares da época. Tampouco o real impacto que elas tiveram nessas regiões. Como sabemos, não existe verdade em História. Na esteira de um processo narrativo, o historiador opera com base em evidências, indícios, sinais, pistas, etc. Valendo-nos, portanto, da suposição histórica, é possível inferir que impressos como estes, ou seja, dedicados à difusão do ideário nacionalista e de culto à imagem de Vargas, não tenham se restringido aos limites impostos pelos muros escolares. Muito provavelmente, tenham chegado, inclusive, às famílias de crianças e jovens em idade escolar.

Resta-nos, por fim, considerar que este artigo procurou apresentar um ensaio de possibilidades historiográficas acerca das cartilhas escolares. Novas perspectivas de análise podem e devem ser realizadas a partir desta tipologia documental. Sobretudo, no que diz respeito à produção editorial, apropriação da leitura, práticas de leitura, bem como estratégias editoriais e de circulação dos livros e/ ou impressos.

\section{Referências}

ABREU, Luciano Aronne de. Estado Novo, realismo e autoritarismo político. Política e Sociedade, n. 12, p. 49-66, abr.2008.

ALMEIDA FILHO, Orlando José de. Historiografia, história da educação e pesquisas sobre o livro didático no Brasil. 2007. Disponível em: 
$<$ http://www.iptan.edu.br/publicacoes/saberes_interdisciplinares/pdf/revista01/Historiog. pdf>. Acesso em: 14 jul. 2014.

BARROS, José D’Assunção. A Nova História Cultural - considerações sobre o seu universo conceitual e seus diálogos com outros campos históricos. Cadernos de História, Belo Horizonte, v. 12, n. 16, p. 38-63, $1^{\circ}$ sem. 2011.

BARROSO, Alfredo. Getúlio Vargas para crianças. Rio de Janeiro: Empresa de Publicações Infantis, 1942.

BICCAS, Maurilane de Souza; Roger Chartier: contribuições para a história da educação. In: LOPES, Eliane Marta Teixeira; FARIA FILHO, Luciano Mendes de. (Orgs.). Pensadores sociais e história da educação II. 2. ed. Belo Horizonte: Autêntica Editora, 2012, p. 269296.

GETÚLIO Vargas: o amigo das crianças. Rio de Janeiro: DIP, 1940.

BURKE, Peter. O Que é história cultural? Rio de Janeiro: Zahar, 2005.

CAPELATO, Maria Helena Rolim. Ensino primário franquista: os livros escolares como instrumento de doutrinação infantil. Revista Brasileira de História, Rio de Janeiro, v. 29, n. 57, p. 117-143, 2009.

CARVALHO, Marta Maria Chagas de. A Escola Nova e o impresso: um estudo sobre as estratégias editoriais de difusão do escolanovismo no Brasil. In: FARIA, Luciano Mendes (Org.). Modos de ler, formas de escrever: estudos da história da leitura e da escrita no Brasil. Belo Horizonte: Autêntica, 1998, p. 65-86.

CATANI, Denice Bárbara; FARIA FILHO, Luciano Mendes de. Um lugar de produção e a produção de um lugar: a história e a historiografia divulgadas no GT História da Educação da ANPEd (1985-2000). Revista Brasileira de Educação, Rio de Janeiro, n. 19, p. 113 -128 Jan./Abr. 2002.

CHARTIER, Roger. (Org.). Práticas de leitura. São Paulo: Estação Liberdade, 1996.

CHARTIER, Roger. Escutar os mortos com os olhos. Estudos Avançados, São Paulo, v. 24, n. 69, p. 7-30, 2010.

CHARTIER, Roger. História cultural: entre práticas e representações. Rio de Janeiro: Bertrand, 1990.

CHARTIER, Roger. Os desafios da escrita. São Paulo: UNESP, 2002.

COELHO, Nelly Novaes. $O$ conto de fadas: símbolos, mitos, arquétipos. São Paulo: Paulinas, 2003.

CHOPPIN, Alain. História dos livros e das edições didáticas: sobre o estado da arte. Educação e Pesquisa, São Paulo, v. 30, n. 3, p. 549-566, set./dez. 2004. 
CORRÊA, Rosa Lydia Teixeira. O livro escolar como fonte de pesquisa em História da Educação. Cadernos Cedes. Campinas, ano XX, n. 52, p. 11-24, nov. 2000.

COSTA, Célio Juvenal et al. (Org.). Fontes e métodos em história da educação. Dourados: UFGD, 2010.

FONSECA, Thais Nívia de Lima e. História da educação e história cultural. In: VEIGA, Cynthia Greive; FONSECA, Thais Nívia de Lima e (Orgs.). História e historiografia da educação no Brasil. Belo Horizonte: Autêntica, 2008, p. 49-76.

GALVÃO, Ana Maria Oliveira; BATISTA, Antônio Augusto Gomes. Manuais escolares e pesquisa histórica. In: VEIGA, C. G.; FONSECA, T. N. de L (Org.). História e historiografia da educação no Brasil. Belo Horizonte: Autêntica, 2008, p. 161-188.

GOMES, Ângela de Castro. As aventuras de Tibicuera: literatura infantil, história do Brasil política cultural na Era Vargas. Revista USP, São Paulo, n. 22, p. 116-133, 2003.

GOMES, Ângela de Castro. Autoritarismo e corporativismo no Brasil: o legado de Vargas. Revista USP. São Paulo, n. 65, p. 105-119, 2005.

HALL, Stuart. A identidade cultural na pós-modernidade. Rio de Janeiro: DP\&A, 2011.

HUNT, Lynn. A nova história cultural. 2. ed. São Paulo: Martins Fontes, 2001.

JÚNIOR, Gonçalo. A guerra dos gibis: a formação do mercado editorial brasileiro e a censura aos quadrinhos, 1933-64. São Paulo: Companhia das Letras, 2004.

LENHARO, Alcir. Sacralização da política. 2. ed. Campinas: Papirus, 1986.

MACIEL, Francisca Izabel Pereira et al. Livros de leitura brasileiros: repositório de moralidade, piedade, amor à família e à pátria. Rede de Estúdios en Lectura y Escritura. Biblioteca Virtual. 2014. Disponível em:

http://hum.unne.edu.ar/investigacion/educa/web_relee/archivos/lec_man_esc.pdf. Acesso em 15 ago. 2014.

MORAES, Maria Célia Marcondes de. Reformas de ensino, modernização administrada. A experiência de Francisco Campos: anos vinte e trinta. Florianópolis: UFSC, Centro de Ciências da Educação, Núcleo de Publicações, 2000.

NAGLE, Jorge. Educação e sociedade na Primeira República. 2. ed. Rio de Janeiro: DP\&A, 2001.

NUNES, Clarice; CARVALHO, Marta. Historiografia da Educação e Fontes. Cadernos ANPED. Porto Alegre, n. 5, p. 7-64, 1993.

OLIVEIRA, Lúcia Lippi. A questão nacional na Primeira República. São Paulo: Brasiliense, 1990. 
SAVIANI, Dermeval et al. Sociedade Brasileira de História da Educação: constituição, organização e realizações. Revista Brasileira de História em Educação, Maringá, v. 3, n. 11, p. 13-45, set./dez. 2011.

SCHMITZ, Zenaide Inês; COSTA, Miguel Ângelo Silva da. Ensino primário getulista: cartilhas escolares como instrumento de doutrinação infantil. In: CONGRESSO INTERNACIONAL DE HISTÓRIA, CULTURA, SOCIEDADE E PODER, 4, 2014, Jataí. Anais... [S.I.: S.n.], 2014 .

SCHWARTZMAN, Simon; BOMENY, Helena Maria Bousquet; COSTA, Vanda Maria Ribeiro. Tempo de Capanema. São Paulo: Paz e Terra: 2000.

SOUZA, Rogério Luiz. A arte de disciplinar os sentidos: o uso de retratos e imagens em tempos de nacionalização (1930-1945). Revista Brasileira de Educação, Rio de Janeiro, v. 19, n. 57, p. 399-416, abr./jun. 2014.

VEIGA, Cynthia Greice. História da educação. São Paulo: Ática, 2007.

VIDAL, Diana Gonçalves. Práticas de leitura na escola brasileira nos anos de 1920 e 1930. In: FARIA FILHO, Luciano Mendes de (Org). Modos de ler/formas de escrever: estudos de história da leitura e da escrita no Brasil. Belo Horizonte: Autêntica, 1998, p. 87-116.

VIDAL, Diana Gonçalves; FARIA FILHO, Luciano Mendes de. As lentes da história: estudos de história e historiografia da educação no Brasil. São Paulo: Autores Associados, 2005.

VIDAL, Diana Gonçalves; FARIA FILHO, Luciano Mendes de. História da educação no Brasil: uma constituição histórica do campo (1880-1970). Revista Brasileira de História. Rio de Janeiro, v. 23, n. 45, p. 37-70, maio/ago. 2003.

XAVIER, Libânia; CARVALHO, Fábio Garcez de. Pesquisa educacional, história da educação e historiografia: diálogo em curso, intercâmbios possíveis. Cadernos de História da Educação, Uberlândia, v. 12, n. 1, p. 231-251, jan./jun. 2013.

Universidade do Estado de Santa Catarina - UDESC Programa de Pós-Graduação em Educação - PPGE

Revista Linhas

Volume 18 - Número 36 - Ano 2017 revistalinhas@gmail.com 